\title{
MOM, apple pie and the girl next door
}

\section{Michael Moon}

is President \& CEO of GISTICS Inc., and is recognised by executives worldwide as a leading international authority on global multichannel brands and digital asset management. McGraw-Hill and its international affiliates now offer his book Firebrands: Building Brand Loyalty in the Internet Age in 13 languages. He chairs the prestigious international conferences on marketing operations management and digital asset management, and serves as the Editor-in-Chief of the Journal of Digital Asset Management.

\section{INTRODUCTION}

Continuous improvement and the overall competitiveness of markets today compel many marketing managers to find ways to use technology, speeding product launches, reducing costs, enhancing customer value and, ultimately, winning more business.

So many options, operational requirements, and 'good ideas' about how to proceed often induce marketing executives to hit the pause button, and immerse themselves in obviously more productive pursuits (eg, e-commerce, market portals, digital promotions, mobile games etc).

This paper will help clarify a number of common end-user requirements for a new, emerging class of technology: marketing operations management - or MOM for short.

The MOM market includes several subordinate technologies, or 'point solutions' that automate one or two facets of a marketing operation, including digital asset management (DAM), brand asset

President \& CEO, GISTICS Inc, 4171 Piedmont Avenue, Suite 210, Oakland CA 94611. USA

Tel: +15104509999 e-mail: moon@gistics.com management (BAM), marketing resource management (MRM), and partner relationship management (PRM). For many firms, a single point solution may provide much of what they need; other firms may need a more comprehensive, integrated solution. So how can one

determine which way to go?

\section{WHAT AILS YOU?}

In GISTICS Inc.'s survey of more 2,500 marketing operations worldwide, it was found that pursuit of a technology without a firm grounding in the 'why' will lead a firm into certain disaster or a quagmire. So let's start with a few big whys.

Marketing drives growth, allocating finite and often scarce resources to maximise competitive advantage. This entails the execution of a brand-marketing strategy across multiple markets, communication channels and collateral formats. Successful execution of strategy requires speed, accuracy, quality and feedback. Senior marketing executives see increasing levels of competition and complexity of marketing communications as a key hindering factor to successful strategy execution.

Addressing these hindering factors gives rise to a master change agenda - how must a marketing operations transform itself into a more integrated, effective system. Figure 1 depicts this master change agenda, calling attention to four strategies for MOM. 


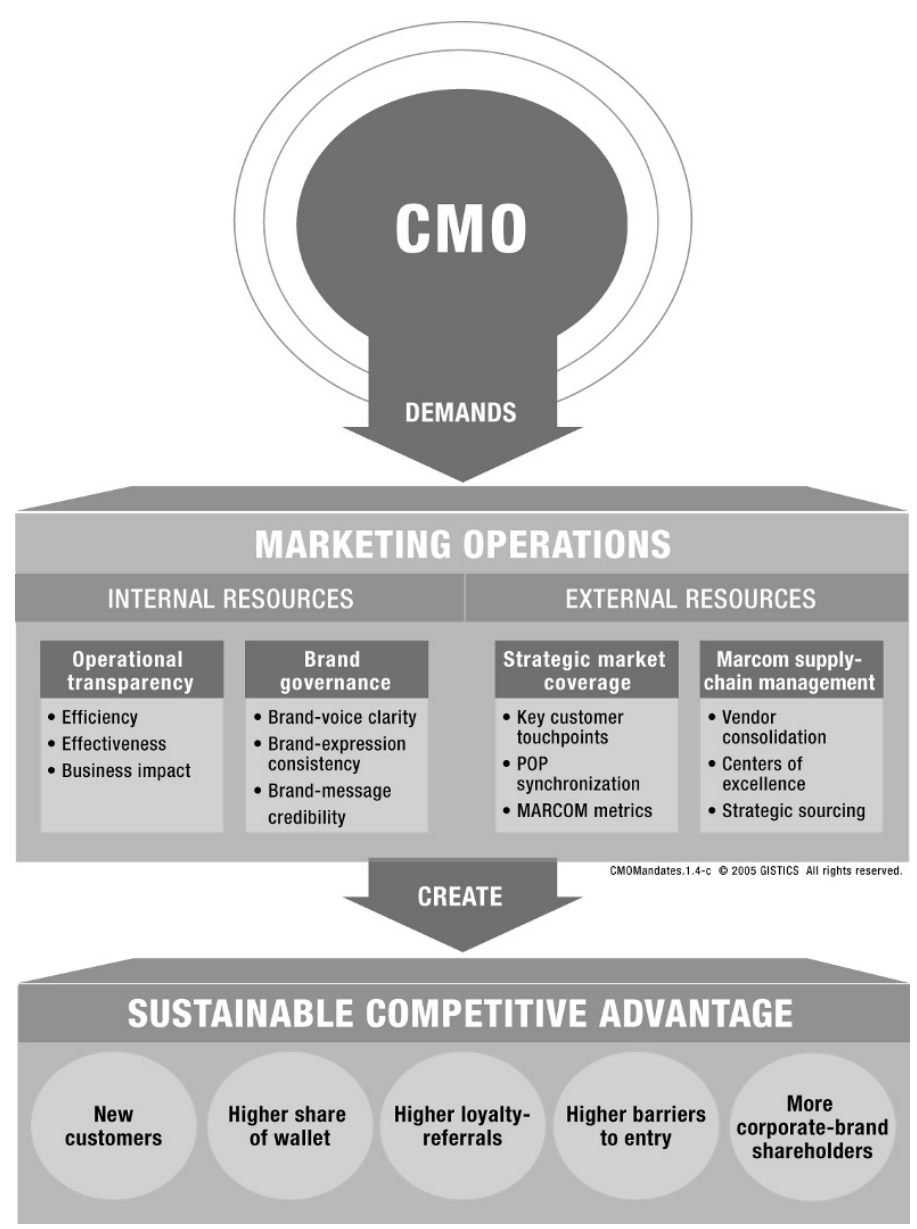

Figure 1: Chief marketing officers worldwide want ways to maximise the sustainable competitive advantage, pursuing a master change agenda with up to four strategic themes Note: $\mathrm{POP}=$ point of purchase

\section{CMO MANDATE}

Chief marketing officers (CMOs) must now justify marketing investments to their corporate boards, emphasising stringent demands for return on investment.

In a number of cases uncovered by GISTICS' research, corporate boards have begun asking CMOs to run marketing more like a factory: given incremental investment of $\mathrm{X}$, what additional top-line growth can you deliver? In turn, CMOs emphasise one or a combination of four strategies for transforming their marketing operations.

\section{Operational efficiency}

Operational efficiency emphasises three comprehensive online summaries of operational performance, presented to the $\mathrm{CMO}$ in the form of a graphical dashboard:

- Efficiency reports - summarise key performance indicators (KPIs) such as current expenditures to budget, breaking out spend-to-plan figures by markets, brands, channels, media, production and partners.

- Effectiveness reports — summarise KPIs such as sales and sales leads created, breaking out figures by 
markets, brands and partners as well as by other key indicators such as web traffic and opt-ins and call centre traffic.

- Business impact reports - summarise KPIs such as dealflow and load capacity utilisation, breaking out current and estimated demands for service at key points of purchase and through post-purchase fulfilment.

In general terms, the change agenda that makes operational transparency its top priority entails the consideration of specialised software for budgeting, planning, campaign management, project management, procurement and measurement. Our research reveals that success often requires a radical change in the procurement of creative services, marketing content and production services as well as a wholesale transformation in the planning and budgeting process, shifting away from spreadsheets and email and towards an integrated suite of online tools.

\section{Brand governance}

Brand governance emphasises three strategic concerns:

- Brand-voice clarity - describes KPIs that correlate website interactions and market survey data with changes in brand awareness and association with key brand values. Brand-voice clarity begins with a unified brand identity system and technical means for ensuring high-fidelity expression across multiple markets, channels and collateral formats.

- Brand-expression consistency describes KPIs for tracking the number and type of inconsistencies among all marketing and corporate communications. These KPIs embrace the idea that 'everything communicates,' whether the firm intended to communicate or not.

- Brand-message credibility - describes the KPIs for tracking levels of acceptance, trust and advocacy among key stakeholder groups and market segments. Often, achieving brand-message credibility requires simplification of the brand story, optimising the brand voice for word-of-mouth propagation and easy comprehension among communities with limited proficiency in English. We assume, of course, that the firm has great products that address all customer requirements and elicit a 'wow' among its users or clients!

The change agenda that makes brand governance a top priority entails a comprehensive brand management discipline incorporating a robust, multichanel brand architecture suitable for clear, consistent expression across all communication channels. This brand management discipline starts with a 'brand bible' or compass, and follows with training, peer-level support programmes, and certification of 'good brand practice.' Many management systems (BAM, DAM, MRM, MOM) support the brand bible and basic training, none provides a comprehensive brand governance solution. These comprehensive systems evolve over long periods of time and demand a real commitment to training and certificating the field marketing staff and partners.

\section{Strategic market coverage}

Strategic market coverage emphasises three strategic concerns:

- Key customer touchpoints summarise KPIs such as the number of impressions and interactions in a market, breaking out the number and 
type of brand interactions by channel, media and customer segment.

- Point-of-purchase synchronisation summarises KPIs such as levels of immersion by market, brand etc.

- Marketing communication (Marcom) metrics - summarise KPIs for correlating vendor performance with efficiency scorecards and brand-marketing strategy with effectiveness scorecards.

The change agenda that makes strategic market coverage a top priority entails synchronised and rapid execution across multiple markets, multiple communication channels (print, online, broadcast) and multiple marcom formats (brochures, direct mail, trade promotions, point-of-purchase materials and multimedia content for the web and mobile devices). This means removing redundant manual procedures and activity-task duplications associated with the time- and cost-intensive production and sourcing of collateral across global markets, multiple channels and various collateral formats. Success with this strategic theme will require centralised, automated collateral production that incorporates best practices and self-service for on-demand marcom portals the functions of what we call a 'Smart Marcom Factory'. A thorough examination of the total lifecycle cost of a smart marcom factory often precludes an internal deployment. Many firms should, however, consider outsourcing this entire function to a centralised marcoms operation.

\section{Management of the supply chain}

Management of the marcom supply chain emphasises three strategic initiatives:

- Vendor consolidation - lays the foundation for more competitive procurement processes. Chosen vendors must invest in a more automated procurement processes.

- Centres of excellence (COE) describe the types of vendors or suppliers to which large brand-marketing firms must outsource critical workflows.

- Strategic sourcing - describes competitive bidding among a few qualified suppliers that have integrated their operations with an interactive bidding and procurement system. For many firms, the strategic sourcing of indirect spend - most notably on marketing communications - remains the last sizable bastion of operational nontransparency, a primary management concern.

The change agenda that makes marcom supply chain management a top priority starts with a DAM repository and the restructuring of creative agency contracts. The DAM provides a centralised collection (see Figure 2).

In the words of a GISTICS, Inc. White Paper:

DAM calls attention to another crucial aspect of strategic sourcing: metatagging, where descriptive information is attached to each asset within the DAM. Strategic sourcing becomes a long-term value-added with how the marcom group buys creative services and marketing content. Marcom needs to specify in each of its agency contracts and contractor's statements of work that: 'We will pay you when you have uploaded your files into our DAM system and cataloged them with the specified metadata and specified dimensions, formats and colour models.

We know of several advertising agencies that have taken a leadership role in metatagging, taking on the role of metadata architects and cataloguers. Under this arrangement, the client outsources metatagging to the agency, paying the agency for one full-time librarian to wrangle assets. Once collected, processed and metatagged, the agency pushes XML-tagged 

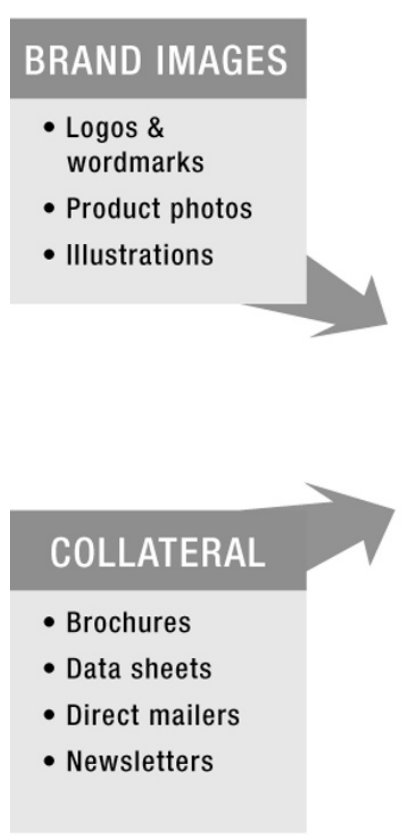
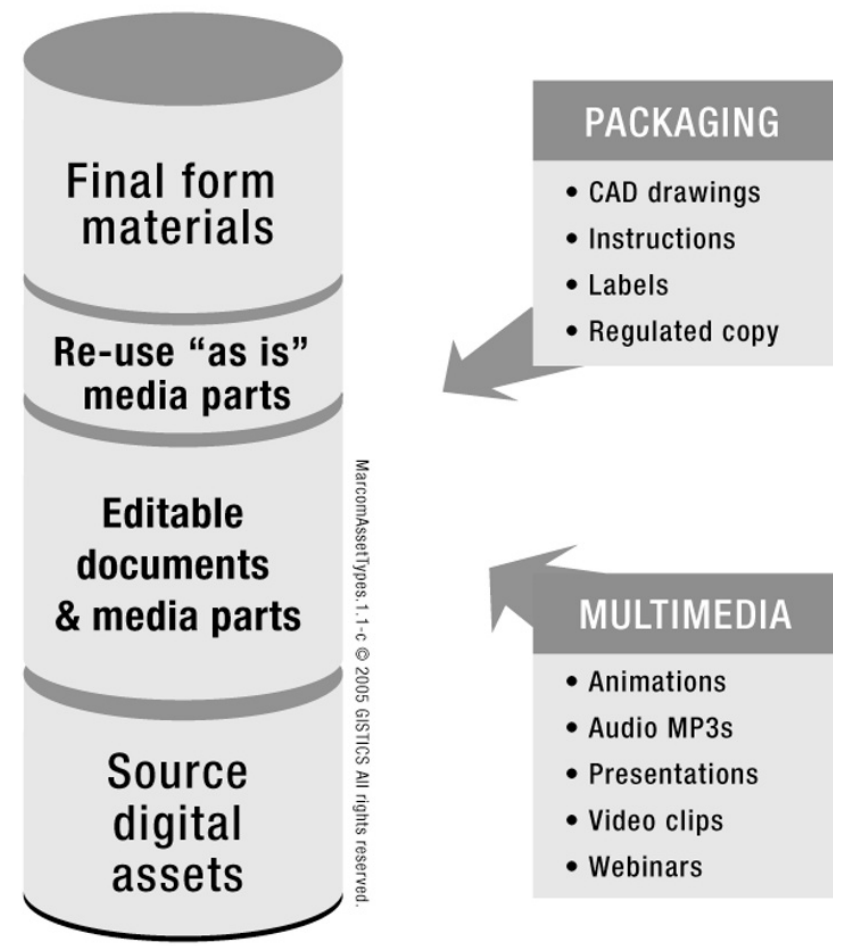

\section{Marcom digital asset repository}

Figure 2: Marcom digital asset repository

DAM repositories provide a centralised collection of marketing-related resources and global access to individual items by authorised users, saving time and money as well as speeding global product launches and time-to-market with essential selling images and collateral

assets into their clients DAM as well as their client's marketing services portals.

In summary, metatagging should start at the earliest point in the digital asset lifecycle.

Metatagging requires a pre-established metadata schema. We recommend the creation of metadata containers with throw-away proxies and an automated search-and-replace procedure. If possible, we recommend that you restructure your agency and creative partner contracts, pushing to them the timely and accurate metatagging of their work products. Your fact-based accounting of the time it takes to upload and catalog an asset provides the baseline for negotiation, and which party will take on cataloguing costs as an incremental charge or as a cost of doing business. ${ }^{1}$

\section{BUYING DECISIONS}

In our work with clients, we have facilitated a broad range of changes within their marketing operations. As a general rule, successful and sustainable organisational change occurs from the bottom up; this of course requires sponsorship from the top down.

Successful bottom up organisational change within a marketing operation requires several success factors, including:

- Thorough consensus on the 'current state' — what's missing, what's needed, and what's broken.

- A working hypothesis about the 'future state' that all affected parties can agree to, move forward on and validate.

- A master plan compromised of several meaningful 60- to 90-day projects with clear and unambiguous accountability and tangible, measurable business benefits. 

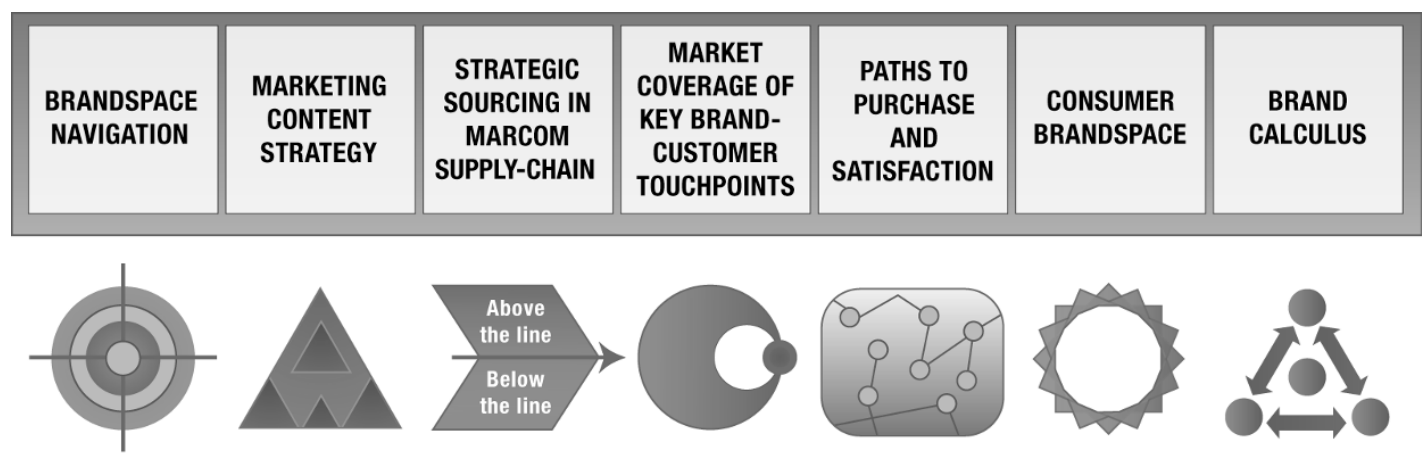

\begin{tabular}{|c|c|c|c|c|c|c|}
\hline $\begin{array}{l}\text { Comprehensive } \\
\text { delineations of } \\
\text { corporate and } \\
\text { brand strategies } \\
\text { and how to apply } \\
\text { marketing } \\
\text { resources for } \\
\text { maximum } \\
\text { competitive } \\
\text { advantage }\end{array}$ & $\begin{array}{l}\text { Technical } \\
\text { specifications for } \\
\text { each brand } \\
\text { marketing } \\
\text { communication; } \\
\text { includes data } \\
\text { content model for } \\
\text { all "semantically } \\
\text { complete data } \\
\text { elements" or } \\
\text { reusable digital } \\
\text { assets used in } \\
\text { online, print, } \\
\text { broadcast, POP } \\
\text { or packaging }\end{array}$ & $\begin{array}{l}\text { Unified campaign } \\
\text { and project } \\
\text { management; } \\
\text { includes DAM, } \\
\text { workflow } \\
\text { automation and } \\
\text { collaboration; } \\
\text { technical } \\
\text { specifications } \\
\text { include a uniform } \\
\text { sourcing process } \\
\text { with federal data } \\
\text { dictionary for all } \\
\text { purchase order } \\
\text { and invoice line } \\
\text { items sourced } \\
\text { from marcom } \\
\text { supply-chain }\end{array}$ & $\begin{array}{l}\text { Comprehensive } \\
\text { delineation of } \\
\text { corporate and } \\
\text { brands-marketing } \\
\text { communications; } \\
\text { includes technical } \\
\text { specification for } \\
\text { measuring } \\
\text { operational } \\
\text { efficiency and } \\
\text { communication } \\
\text { effectiveness by } \\
\text { type of customer } \\
\text { or channel } \\
\text { partner }\end{array}$ & $\begin{array}{l}\text { Technical } \\
\text { specifications for } \\
\text { behavioral-data } \\
\text { collection for } \\
\text { all corporate and } \\
\text { brand-marketing } \\
\text { communications; } \\
\text { data reporting } \\
\text { emphasizes the } \\
\text { measurement of } \\
\text { operational } \\
\text { efficiency and } \\
\text { communication } \\
\text { effectiveness } \\
\text { by type of } \\
\text { customer or } \\
\text { channel partner }\end{array}$ & $\begin{array}{l}\text { Technical } \\
\text { specifications for } \\
\text { tracking brand } \\
\text { awareness, } \\
\text { preference, } \\
\text { repurchase, and } \\
\text { referrals, as well } \\
\text { as third-party } \\
\text { interventions } \\
\text { (intermediaries } \\
\text { influencing brand } \\
\text { equity) }\end{array}$ & $\begin{array}{l}\text { Psychometric } \\
\text { specifications for } \\
\text { correlatin brand- } \\
\text { values and } \\
\text { service- } \\
\text { satisfactions the } \\
\text { social identities } \\
\text { (or cultural norms } \\
\text { and business } \\
\text { models) } \\
\text { of customers }\end{array}$ \\
\hline
\end{tabular}

Figure 3: A marcom supply chain consists of several technical systems each of which produces data. The model depicted above draws attention to seven systems that, when integrated, enable the execution of a marcom supply chain strategy

- Small, tight-knit teams with the primary accountability for driving ONE 60- to 90-day project to successful completion.

Generally, we have found that a lack of agreement about the current state remains the most challenging part of the process. Most firms do not have structured, repeatable processes for documenting a current state within a solution-oriented framework. This requires a methodology for modeling workflows and the (hidden and deadly) 'carbon monoxide' costs of a supply chain. Figure 3 depicts a technical framework for the marcom supply chain, emphasising seven areas with opportunities for automation.

\section{Brandspace navigators}

These provide detailed technical descriptions of every meaningful element of a brand, demonstrating how to express a brand voice with clarity, consistency and credibility. Brandspace navigators give marketing staff and partners the information and examples that they need to co-market a new product with another partner. Brandspace navigators also deliver distance learning, testing and assessment and certification of a particular firm's way of brand-building.

\section{Marketing content strategies}

These provide blueprints for automating multichannel publishing workflows and the strategic sourcing of marketing 
content among a network of certified vendors. A data content model plays a central role in the execution of marketing content strategies, which specifies how each element of the marketing collateral fits together into a seamless whole (eg, brochures, direct mailers, catalogues).

\section{Strategic sourcing in marcom supply chains}

Strategic sourcing submits every creative or production project to competitive bidding and paperless procurement and payment systems. It requires a unified process for defining and managing campaigns and related products. Uniform processes depend on a federal data dictionary that defines each element of a vendor's bid, order confirmation and invoice; this enables company-wide reporting and analysis.

\section{Market coverage tracking of key brand-customer touchpoints}

This entails the definition of technical specifications for measuring operational efficiency and communication of effectiveness by type of customer, channel and marketing communication. Market coverage tracking takes consumer behaviour analysis to the next level, emphasising brand interactions throughout a lifecycle model.

\section{Paths to purchase and satisfaction}

These define how to track customer behaviours throughout the buying and using phases of a customer lifecycle model. Paths to purchase and satisfaction models correlate satisfaction, loyalty and customer referrals to demographic and psychographic consumer models.

\section{Consumer brandspace}

This defines the technical specifications for tracking a company's brand among other brands and, specifically, how consumers position various brands in their own mental space.

\section{Brand-value calculus}

Brand-value calculus completes the roadmap for marketing operations, defining how customers experience a brand-marketing effort - the cognitive science and neurolinguistics of a brand's voice and cultural icons.

\section{SUMMARY}

Determining the current state of a marketing operation remains job number one. A clear-headed focus on bottom up change suggests starting with marcom supply chain management, driving out needless cost and poor performance. This will require a DAM repository and a restructuring of the way in which the firm sources creative services, marketing content and production services. In turn, metadata framework for your marcom assets must be developed - the first of seven business intelligence data systems. With marcom assets secure and easily retrieved, we suggest that you tackle brand governance, framing the work of a front-end brand-space navigator and the end-of-chain brand calculus. This should provide clarity as to the next steps and how to proceed with 60- to 90-day high-velocity projects.

\section{Reference}

1 Moon, M. and Warwick, J. (2005) 'Opportunities and challenges for marcom supply-chain management', White Paper, GISTICS, Inc., Oakland, CA. 